\title{
Correspondence
}

\section{Analgesic effects of thoracic epidural bupivacaine and fentanyl}

\section{To the Editor:}

The use of epidural narcotics for analgesia after thoracotomy is a well accepted technique. Epidural analgesia studied in the postthoracotomy patient usually involves fentanyl alone or with bupivacaine in concentrations up to $12.5 \mu \mathrm{g} \cdot \mathrm{ml}^{-1}$ at rates up to $1.9 \mu \mathrm{g} \cdot \mathrm{kg}^{-1} \cdot \mathrm{hr}^{-1} .1,2$

We would like to report the use of bupivicaine $0.1 \%$ and fentanyl $2 \mu \mathrm{g} \cdot \mathrm{ml}^{-1}$ infusion administered via a thoracic epidural for postthoracotomy pain. Informed consent was obtained from all patients. Fifteen ASA physical status I-III patients who were scheduled for elective thoracotomy were studied. The only anaesthetic restrictions were the administration of opioids and the conduct of the epidural. The epidural catheter was introduced using a midline approach between the fifth and eighth thoracic vertebral interspaces and advanced $2-3 \mathrm{~cm}$ cephalad before induction of anaesthesia. An epidural test dose of $3 \mathrm{ml}$ of $\mathrm{CO}_{2}$ xylocaine $2 \%$ was administered to confirm correct placement of the catheter. Intravenous fentanyl could be administered on or shortly after induction of anaesthesia up to $2 \mu \mathrm{g} \cdot \mathrm{kg}^{-1}$. The initial bolus administered after induction and patient positioning was 15-20 $\mathrm{ml}$ of bupivicaine $0.1 \%$ with $5 \mu \mathrm{g} \cdot \mathrm{ml}^{-1}$, fentanyl. An epidural infusion of bupivacaine and $2 \mu \mathrm{g} \cdot \mathrm{ml}^{-1}$ fentanyl was started at $10 \mathrm{ml} \cdot \mathrm{hr}^{-1}$ intraoperatively. The patients were studied for $24 \mathrm{hr}$ postoperatively and were required to evaluate their pain and level of pruritus using visual analogue scales $(0-10 \mathrm{~cm}$ line). If the VAS pain score was $>3$ the patient was given an epidural bolus of 50-75 $\mu \mathrm{g}$ fentanyl in $10 \mathrm{ml}$ saline and the infusion was increased to $15 \mathrm{ml} \cdot \mathrm{hr}^{-1}$. If the VAS pain score was still $>3$ the bolus dose was repeated and the infusion increased to $20 \mathrm{ml} \cdot \mathrm{hr}^{-1}$. Nalbuphine $10-20 \mathrm{mg}$ iv could be administered for nonincisional pain and diphenhydramine 50 mg followed by naloxone $0.1 \mathrm{mg} i v$ for treatment of pruritus. The VAS pain and pruritus scores were done every six hours or after any of these medications were administered. All patients achieved excellent analgesia (VAS $<3$ ) during the study period. Eight patients required only the basal infusion rate. Five more were analgesic with infusion rates of $<15 \mathrm{ml} \cdot \mathrm{hr}^{-1}$. Two patients required an infusion of $20 \mathrm{ml} \cdot \mathrm{hr}^{-1}$. Only three patients (20\%) required treatment for pruritus (VAS $>3$ ). Neither diphenhydramine nor naloxone seemed to affect the pain scores. Five patients maintained a $\mathrm{PCO}_{2}$ between 45 and 58 or $\mathrm{pH}<7.35$.

We believe the described technique is efficacious in providing effective postoperative analgesia for thoracotomy utilizing fentanyl at a concentration and dosage lower than previously described. This reduced fentanyl dose was at the cost of a higher dose of bupivacaine by virtue of the high volumes infused. ${ }^{1-3}$ Whether or not this relates to any improverment in morbidity or compares to other analgesic techniques will require more study.

\author{
Elliot T. Hudes MD FRCPC \\ Gail M. Hirano MD FRCPC \\ Brian A. Kashin MD FRCPC \\ Ken Ho MD FRCPC \\ I. Ashley MacDonald MB ChB FRCA \\ Kevin Shine BSc MD FRCP \\ Peel Memorial Hospital \\ 20 Lynch St. \\ Brampton, Ontario L6W 2Z8
}

\section{REFERENCES}

1 Salomaki TE, Laitinen JO, Nuutinen LS. A randomized double-blind comparison of epidural versus intravenous fentanyl infusion for analgesia after thoracotomy. Anesthesiology 1991; 75: 790-5.

2 Sandler AN, Stringer D, Panos $L$, et al. A randomized, double-blind comparison of lumbar epidural and intravenous fentanyl infusions for postthoracotomy pain relief. Anesthesiology 1992; 77: 626-34.

3 George KA, Wright PMC, Chisakuta A. Continuous thoracic epidural fentanyl for post-thoracotomy pain relief: with or without bupivacaine. Anaesthesia 1991; 46: 732-6.

\section{Tracheal granulations secon- dary to wall compression by endotracheal tubes in infants}

To the Editor:

Tip stenosis is a complication of tracheal intubation. We report here two infants who suffered airway stenosis caused by tracheal granulation resulting from compression of the anterior tracheal wall between the dilated pul- 